\title{
Fascin expression in dendritic cells and tumor epithelium in thymoma and thymic carcinoma
}

\author{
JUNICHIRO SATO ${ }^{1}$, MASACHIKA FUJIWARA ${ }^{2}$, TOMOHIRO KAWAKAMI ${ }^{4}$, \\ AYUMI SUMIISHI ${ }^{2}$, SEIJI SAKATA ${ }^{2}$, ATSUHIKO SAKAMOTO ${ }^{2}$ and ATSUSHI KURATA ${ }^{3}$ \\ ${ }^{1}$ Kyorin University Hospital; ${ }^{2}$ Department of Pathology, Kyorin University School of Medicine; \\ ${ }^{3}$ Department of Molecular Pathology, Tokyo Medical University, Tokyo; ${ }^{4}$ Juntendo University Urayasu Hospital, Chiba, Japan
}

Received March 16, 2011; Accepted August 5, 2011

DOI: $10.3892 / \mathrm{ol} .2011 .383$

\begin{abstract}
The majority of thymomas are histologically characterized by tumor-infiltrating lymphocytes. Mature dendritic cells (DCs) are known to assemble lymphocytes through antigen presentation to $\mathrm{T}$ lymphocytes. Fascin, a 55-kDa actin-binding protein and a known marker for mature DCs, regulates filaments necessary for the formation of filopodia in cell migration. Moreover, fascin expression in various epithelial neoplasms has recently been reported to be associated with invasion of tumor cells and clinically aggressive manifestations. In the present study, we investigated fascin expression immunohistochemically in tissues of thymomas and thymic carcinomas surgically resected at our institute. A total of 34 thymomas and 5 thymic carcinomas were included. The amount and immunohistochemical intensity of both fascin ${ }^{+}$DCs and tumor epithelium were counted and assessed, and the clinicopathological data were also scored. Statistical analyses revealed that the amount of $\operatorname{fascin}^{+}$DCs with the formation of clusters was associated with lymphocyte-rich variants $(p=0.002)$ and cortical differentiation $(p=0.037)$ of thymoma with complication from myasthenia gravis $(p=0.002)$. The quantity of fascin ${ }^{+}$epithelium was associated with a strong intensity of fascin in infiltrating DCs $(\mathrm{p}=0.002)$ with the formation of clusters $(\mathrm{p}=0.002)$ and favorable prognosis, as assessed by the Masaoka staging system $(\mathrm{p}=0.001)$. The amount of infiltrating DCs $(\mathrm{p}=0.024)$ and fascin $^{+}$epithelium were lower in thymic carcinoma. It was concluded that fascin ${ }^{+}$epithelium may induce tumor immunity through the surveillance activity of fascin ${ }^{+}$DCs in thymic neoplasms, thus improving prognosis.
\end{abstract}

Correspondence to: Dr Atsushi Kurata, Department of Molecular Pathology, Tokyo Medical University, 6-1-1 Shinjuku, Shinjuku-ku, Tokyo 160-8402, Japan

E-mail: akurata@tokyo-med.ac.jp

Key words: thymoma, immunohistochemistry, fascin, dendritic cell, tumor immunity

\section{Introduction}

Thymoma is one of the most common tumors in the mediastinum and accounts for $45 \%$ of anterior mediastinal tumors in adults (1). Since it has a variable appearance in histology, it is classified based on the predominant cell types, such as lymphocytic, epithelial or spindle cell variants. Furthermore, a new classification system with the aim of grouping thymomas based on cytological differences has been proposed by the WHO, since a strong association exists between histological subtype and invasiveness as well as prognosis $(2,3)$. The Masaoka staging system, which classifies tumors according to the degree of invasion through the capsule into the surrounding structures, has also been proposed $(1,4,5)$. The Masaoka staging system has been reported to accurately reflect the prognosis of thymoma $(2,6)$. On the other hand, thymic carcinoma is relatively rare and, histologically, it commonly manifests as squamous cell carcinoma or lymphoepitheliomalike carcinoma (2). In contrast to thymoma, thymic carcinoma usually features necrosis, cell atypia and mitosis, and is cytologically and clinically malignant $(1,2)$.

Since divergent infiltration of lymphocytes has been observed in thymoma and thymic carcinoma, it has been postulated that, as with other organs (7), antigen presentation through MHC-II is associated with the amount of tumor-infiltrating lymphocytes, which reflects the above-mentioned histological subtypes. Previously, the association of presumed antigenpresenting cells, which are immunohistochemically positive for CD1a and S100 protein, in thymic neoplasms was investigated (8-10). However, it was subsequently established that CD1a and S100 protein are not specific markers for antigenpresenting cells. Instead, immunohistochemically fascin ${ }^{+}$cells with dendritic morphology were found to be more specific for antigen-presenting mature dendritic cells (DCs) $(11,12)$. We demonstrated the contribution of fascin ${ }^{+}$mature DCs in tumorrelated sarcoid reactions in various types of cancer, which implicated the occurrence of tumor immunity (12).

Fascin is a 55-kDa actin-binding protein and a major regulating factor of the cytoskeleton that localizes to microspikes, filopodia and protrusions under the cytomembrane $(11,13)$. In normal adult human tissues, fascin expression is restricted to neurons and DCs; both cell types have markedly large filopodia and are highly motile $(11,13)$. Fascin expression 
in various neoplastic cells has also been investigated, and its expression has been reported to be associated with epithelial to mesenchymal progression and invasion of tumor cells as well as a clinically aggressive manifestation and poorer prognosis (14-23). However, to the best of our knowledge, immunohistochemical studies for the detection of fascin ${ }^{+}$mature DCs in thymoma have yet to be performed. In addition, fascin expression in the epithelial components of thymomas and thymic carcinomas remains to be investigated. Thus, the present study was designed to assess fascin expression in DCs and tumor epithelia in thymomas and thymic carcinomas.

\section{Materials and methods}

Case selection and immunohistochemistry of fascin. In the present study, resected thymoma and thymic carcinoma specimens were obtained by standard thoracotomies and tumor resections from patients analyzed between 2003 and 2010. Following informed patient consent, the tissues were used for the diagnostic work-up and transferred to the archival files at Kyorin University Hospital, Tokyo, according to the data and ethics protection rules of the Medical Faculty. The tissues were fixed by immersion in $4 \%$ formalin for $24 \mathrm{~h}$ and embedded in paraffin using standard techniques. One representative tissue sample that included the tumor area key to diagnosis was selected in each case. Tissue sections were stained with hematoxylin and eosin. Additionally, the immunohistochemical staining of fascin was performed using a mouse monoclonal anti-fascin antibody (clone 55K-2, dilution 1:500; Dako, Glostrup, Denmark) on 4- $\mu$ m paraffinembedded sections, using a LSAB method by the Nex-ES IHC staining module (Ventana I-VIEW DAB universal kit; Ventana Medical Systems Inc., Tucson, AZ, USA). To expose antigens, sections were autoclaved in citrate buffer ( $\mathrm{pH}$ 6.0) for $10 \mathrm{~min}$ and cooled for $30 \mathrm{~min}$. Nuclear counterstaining was performed with Mayer's hematoxylin. For the negative control, the incubation step with the primary antibody was omitted.

Interpretation of immunohistochemical results of fascin. Light microscopy performed with a Carl Zeiss HAL 100 instrument and W-PI 10x/23 ocular lens was used to analyze and quantitate the immunohistochemical data. With regard to the number of fascin-positive DCs (fascin ${ }^{+}$DCs) in each preparation, immunopositive cells with dendritic morphology were counted in $1 / 16 \mathrm{~mm}^{2}$ squares within 8 randomly selected fields using x400 magnification, and the sum of all cell counts within a total of $0.5 \mathrm{~mm}^{2}$ tissue area was allocated a point score as follows: $0-40$ cells, 0 ; $41-80$ cells, 1 ; 81-120 cells, 2; and $>120$ cells, 3 . Fascin ${ }^{+}$DCs occasionally formed a cluster, where they aggregated and were arranged at even intervals (DC-cluster). These clusters were analyzed in detail, and the mean interval between neighboring DCs was measured in each preparation using $\mathrm{x} 400$ magnification. The ratio of the area where DCs formed clusters to the total tumor area (DC-cluster ratio) was then assessed in each preparation using x100 magnification and allocated a point score as follows: $0-25 \%, 0 ; 26-50 \%, 1 ; 51-75 \%, 2$; and $76-100 \%, 3$. The amount of fascin ${ }^{+}$tumor epithelium was assessed as a ratio of positive cell components to total epithelial components in each preparation using x100 magnification and scored as above: 0-25\%,
$0 ; 26-50 \%, 1 ; 51-75 \%, 2$; and $76-100 \%, 3$. Using the positively stained blood vessel endothelial cells as an internal control, the intensity of positive staining in DCs and tumor epithelium was assessed (intensity of DCs and intensity of epithelium, respectively) and allocated a point score as follows: negative, 0 ; less than the control, 1; equal to the control, 2; and more than the control, 3, according to the established counting system of fascin intensity (16). In specimens where normal thymus were included, fascin expression in infiltrating DCs and normal thymic epithelium as well as immunoreactive intensity were assessed, but they were not allocated characteristic point scores since these factors were generally negligible in normal thymus.

Clinicopathological and statistical analysis. Clinicopathological information was allocated point scores as follows. For the patients' gender, scores were assigned as male, 0 or female, 1 . Scores for patients' age were assigned according to years: $<40,0 ; 40-49,1 ; 50-59,2 ; 60-69,3 ; 70-79,4$; and >79, 5 . Complications from myasthenia gravis were assessed and scored as absent, 0 or present, 1 . Limited to the cases in which lymph node dissection was performed, lymph node metastasis was graded as (-), 0 or (+), 1. The Masaoka staging system was also utilized and scored as: stage 1, 0; stage 2, 1; stage 3, 2; stage 4a, 3; and stage 4b, 4. The maximum diameter of the tumor (tumor diameter) was graded as: $<3 \mathrm{~cm}, 0 ; 3.1-6 \mathrm{~cm}$, 1; 6.1-9 cm, 2; 9.1-12 cm, 3; 12.1-15 cm, 4; or >15 cm, 5. The histology of the tumor was subdivided and scored in various ways. First, differentiation between thymoma and thymic carcinoma (thymoma vs. carcinoma) was assessed and scored as thymoma, 0 or thymic carcinoma, 1 . Second, limited only to thymoma, 'histological variants' were assigned point scores as: lymphocytic-predominant (Type B1), 0; intermediate (Types AB and B2), 1; and thymic epithelial-predominant (Types A and B3), 2 (24). For thymoma alone, histology based on the origin of thymic epithelium (epithelial origin) was graded as: medullary epithelium (Type A), 0; mixed (Type AB), 1; or cortical epithelium (Types B1, B2 and B3), 2 (3). Based on the point scores described above, statistical analyses using Spearman's rank correlation was performed with the SPSS software package (standard version, release 10.0.7 J; SPSS, Chicago, IL, USA). The data are presented as the means \pm standard deviation where appropriate.

Additional immunostaining for limited cases. To assess the fascin $^{+}$cell types, the most recent case was selected from each diagnostic category (Types A, AB, B1, B2 and B3 thymomas; and thymic carcinoma). For these 6 selected samples, additional immunostainings for S100 protein (polyclonal rabbit, dilution 1:800; Dako), HLA-DR (clone TAL.1B5, dilution 1:1,000; Dako), CD1a (clone MTB-1, dilution 1:25; Novocastra, Newcastle upon Tyne, UK) and cytokeratin AE1/AE3 (clone AE1/AE3, dilution 1/100; Dako), were performed. The abovementioned LSAB method by the Nex-ES IHC staining module was used, with the exception of CDla visualization, which was performed via the polymer peroxidase method (ACUITY Advanced Biotin Free HRP Polymer Detection System; Covance Research Products, Inc., Dedham, MA, USA). For antigen retrieval, tissues for HLA-DR and CD1a immunostainings were autoclaved in citrate buffer ( $\mathrm{pH}$ 6.0) for $10 \mathrm{~min}$ and in 
Table I. Clinicopathological data for analyzed thymomas and thymic carcinomas.

\begin{tabular}{lrccccccc}
\hline $\begin{array}{l}\text { Histological } \\
\text { classification }\end{array}$ & No. & $\begin{array}{c}\text { Gender } \\
\text { (male, } \\
\text { female) }\end{array}$ & $\begin{array}{c}\text { Average } \\
\text { age }\end{array}$ & $\begin{array}{c}\text { Complication } \\
\text { myasthenia } \\
\text { dissection } \\
\text { gravis }(-,+)\end{array}$ & $\begin{array}{c}\text { Lymph node } \\
\text { from metastasis } \\
(-,+, \text { not } \\
\text { performed) }\end{array}$ & $\begin{array}{c}\text { Masaoka } \\
\text { staging system } \\
(1,2,3,4 a, 4 b, \\
\text { not recorded) }\end{array}$ & $\begin{array}{c}\text { Average } \\
\text { tumor's } \\
\text { maximal } \\
\text { diameter }\end{array}$ & $\begin{array}{c}\text { Normal } \\
\text { thymus } \\
\text { tissue }(-,+)\end{array}$ \\
\hline Type A & 4 & $1: 3$ & $70.3 \pm 6.95$ & $4: 0$ & $1: 0: 3$ & $0: 1: 3: 0: 0: 0$ & $5.75 \pm 2.53$ & $3: 1$ \\
Type AB & 12 & $8: 4$ & $56.0 \pm 12.9$ & $11: 1$ & $3: 2: 7$ & $7: 2: 0: 0: 0: 3$ & $6.98 \pm 2.94^{\mathrm{a}}$ & $3: 9$ \\
Type B1 & 1 & $1: 0$ & 36 & $0: 1$ & $0: 0: 1$ & $0: 0: 0: 0: 0: 1$ & 3.5 & $0: 1$ \\
Type B2 & 11 & $9: 2$ & $47.6 \pm 13.7$ & $5: 6$ & $4: 1: 6$ & $4: 4: 2: 1: 0: 0$ & $10.25 \pm 5.56^{\mathrm{a}}$ & $3: 8$ \\
Type B3 & 6 & $4: 2$ & $65.7 \pm 8.52$ & $6: 0$ & $1: 2: 3$ & $2: 2: 0: 1: 1: 0$ & $4.58 \pm 2.06^{\mathrm{b}}$ & $2: 4$ \\
Carcinoma & 5 & $3: 2$ & $63.0 \pm 5.66$ & $5: 0$ & $2: 2: 1$ & $0: 1: 2: 0: 1: 1$ & $7.50 \pm 2.86^{\mathrm{a}}$ & $0: 5$ \\
\hline
\end{tabular}

${ }^{a}$ One of the tumor sizes was not recorded. ${ }^{\mathrm{b}}$ Two of the tumor sizes were not recorded.

Table II. Summary of immunohistochemical results of fascin.

\begin{tabular}{|c|c|c|c|c|c|c|}
\hline \multirow[b]{2}{*}{$\begin{array}{l}\text { Histological } \\
\text { classification }\end{array}$} & \multirow[b]{2}{*}{ No. } & \multicolumn{3}{|c|}{$\mathrm{Fascin}^{+} \mathrm{DCs}$} & \multicolumn{2}{|c|}{ Fascin $^{+}$epithelium } \\
\hline & & $\begin{array}{l}\text { Fascin }^{+} \mathrm{DCs} \\
\left(\text { per } 0.5 \mathrm{~mm}^{2}\right. \\
\text { tissue area) }\end{array}$ & $\begin{array}{c}\text { Intensity of } \\
\text { DCs }\end{array}$ & $\begin{array}{l}\text { Ratio }(\%) \text { of } \\
\text { DC-cluster }\end{array}$ & $\begin{array}{l}\text { Ratio }(\%) \text { of positive } \\
\text { cell component: } \\
\text { Fascin }^{+} \text {epithelium }\end{array}$ & $\begin{array}{l}\text { Intensity of } \\
\text { epithelium }\end{array}$ \\
\hline Type A & 4 & $7.3 \pm 7.4$ & $0.75 \pm 0.96$ & $3 \pm 5$ & $21 \pm 17$ & $0.75 \pm 0.50$ \\
\hline Type AB & 12 & $63.0 \pm 29$ & $2.10 \pm 0.29$ & $53 \pm 22$ & $68 \pm 24$ & $0.91 \pm 0.29$ \\
\hline Type B1 & 1 & 134 & 2 & 100 & 20 & 1 \\
\hline Type B2 & 11 & $80.0 \pm 53$ & $2.00 \pm 0.63$ & $54 \pm 38$ & $44 \pm 37$ & $0.81 \pm 0.40$ \\
\hline Type B3 & 6 & $42.0 \pm 33$ & $2.00 \pm 1.10$ & $41 \pm 37$ & $50 \pm 39$ & $0.67 \pm 0.52$ \\
\hline Carcinoma & 5 & $4.0 \pm 2.6$ & $1.20 \pm 1.10$ & $4 \pm 9$ & $14 \pm 31$ & $0.60 \pm 1.30$ \\
\hline
\end{tabular}

DC, dendritic cell.

citrate buffer ( $\mathrm{pH} 9.0$ ) for 5 min, respectively. Immunopositive cells with dendritic morphology were assessed and compared to those stained for fascin. These cells were also counted in $1 / 16 \mathrm{~mm}^{2}$ squares within 8 randomly selected fields using $\mathrm{x} 400$ magnification. The sum of the cell counts within a total of 0.5 $\mathrm{mm}^{2}$ tissue area was then calculated, except in the assessment of cytokeratin AE1/AE3.

\section{Results}

A total of 34 cases of thymoma and 5 cases of thymic carcinoma diagnosed and resected during the past 8 years at the Kyorin University Hospital were identified and used in this study. The clinical data are shown in Table I. The thymoma cases comprised 23 males and 11 females, whereas the thymic carcinoma cases included 3 males and 2 females. The mean age of thymoma patients was $56.1 \pm 14.3$ years, whereas that of thymic carcinoma patients was $63.0 \pm 5.66$ years. In total, 8 cases with complications from myasthenia gravis were identified, 7 of whom were male patients. In other cases, thymic neoplasms were found incidentally. Lymph node dissection was performed in 18 cases, including 4 thymic carcinomas, and lymph node metastasis was identified in 7 cases, including 2 thymic carcinomas. Normal thymus was included in 28 of the analyzed cases.
The immunohistochemical results for fascin are shown in Table II. Fascin ${ }^{+}$mature DCs were identified in the thymoma and thymic carcinoma specimens, particularly in the regions of lymphocytic infiltration (Fig. 1). Diffuse DC-clusters were observed in Type B1 thymomas (Fig. 2), whereas DC-clusters were identified in regions of cortical differentiation in other types of thymomas. The mean interval between neighboring DCs within the DC-clusters was $25-50 \mu \mathrm{m}$ in each specimen. In normal thymus, DCs in the cortex and medulla were generally positive for fascin (Fig. 3A). Fascin ${ }^{+}$epithelium was observed in all of the thymoma specimens (Figs. 1 and 2), although the immunoreactive intensity was variable and generally weaker than the intensity of DCs. Only 1 out of 5 thymic carcinoma specimens had fascin ${ }^{+}$epithelium, while no epithelial fascin expression was observed in the remaining 4 specimens (Fig. 4).

Correlation coefficients were obtained (Tables III and IV) using these clinicopathological and immunohistochemical data, with plus and minus symbols showing positive and negative correlations, respectively. Only the significant results $(\mathrm{p}<0.05)$ are appointed Spearman's rho ('r'), a non-parametric measure of correlation that assesses how well an arbitrary monotonic function describes the relationship between two variables without making any other assumptions about the 


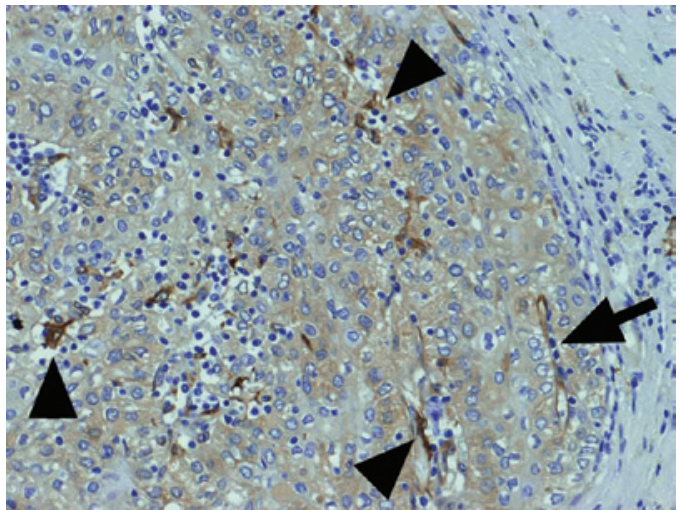

Figure 1. Immunohistochemical expression of fascin in Type B3 thymoma. Fascin $^{+}$DCs (arrowheads) with the same strong intensity as endothelial cells (arrow) were scattered along with lymphocytic infiltration, while the tumor epithelium was weakly stained. Magnification, x200.

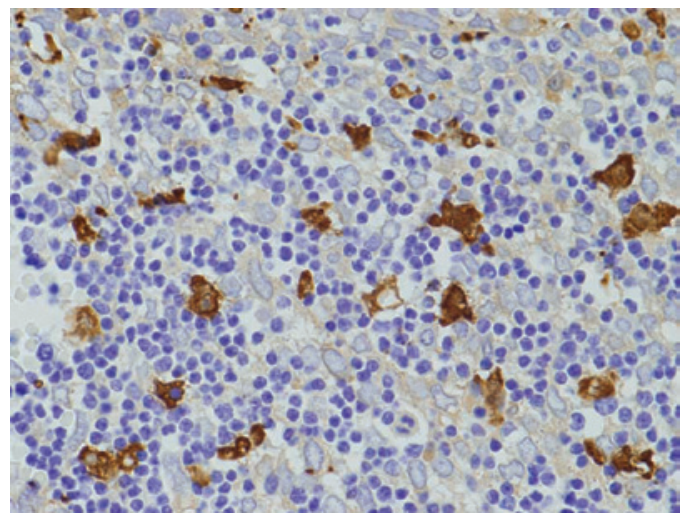

Figure 2. Fascin ${ }^{+}$DCs were arranged at even intervals, forming clusters in Type B1 thymoma. The tumor epithelium was also weakly stained. Magnification, $\mathrm{x} 400$.

particular nature of the relationship between the variables. Table III shows the correlations between the clinicopathological and immunohistochemical data, while Table IV shows the results of mutual correlations between different immunohistochemical data.

As shown in Table III, fascin ${ }^{+}$DCs showed negative correlations with the patients' gender, thymoma vs. carcinoma and histological variants, whereas it demonstrated positive correlations with complication from myasthenia gravis, tumor diameter and epithelial origin. Therefore, fascin $^{+}$DCs appear more frequently in benign thymic neoplasms with a greater diameter, which are lymphocytic-predominant variants and of cortical epithelium origin, and in male patients with complication from myasthenia gravis. Intensity of DCs showed a positive correlation with epithelial origin, while it showed negative correlations with thymoma vs. carcinoma and the Masaoka stage scores. Therefore, DCs with a higher intensity of fascin are characteristic of benign thymic neoplasms of cortical epithelial origin with a lower Masaoka stage. The ratio of DC-cluster inversely correlated with both thymoma vs. carcinoma and histological variants, which was identical to the statistical results of fascin ${ }^{+}$DCs. Both the ratio of fascin ${ }^{+}$ epithelium and intensity of epithelium demonstrated a negative correlation with the Masaoka stage scores, indicating that these
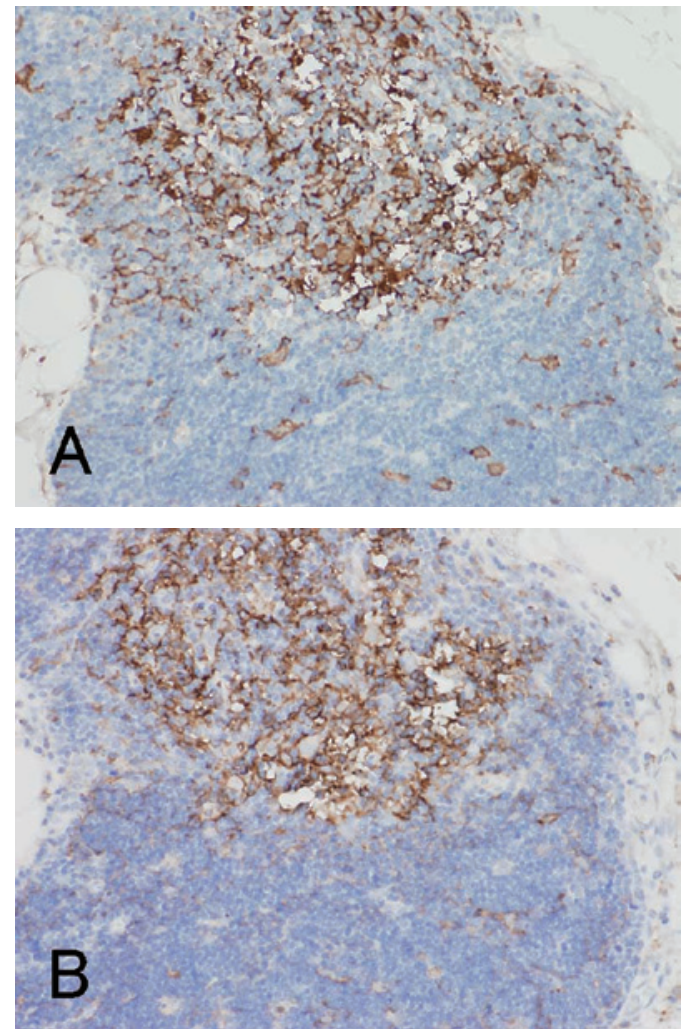

Figure 3. Normal thymus with cortex (lower right) and medulla (upper left). (A) and (B) are the same fields. (A) Fascin ${ }^{+}$DCs were identified in the cortex and medulla. (B) HLA-DR ${ }^{+}$DCs were found only in the medulla. Magnification, x200.

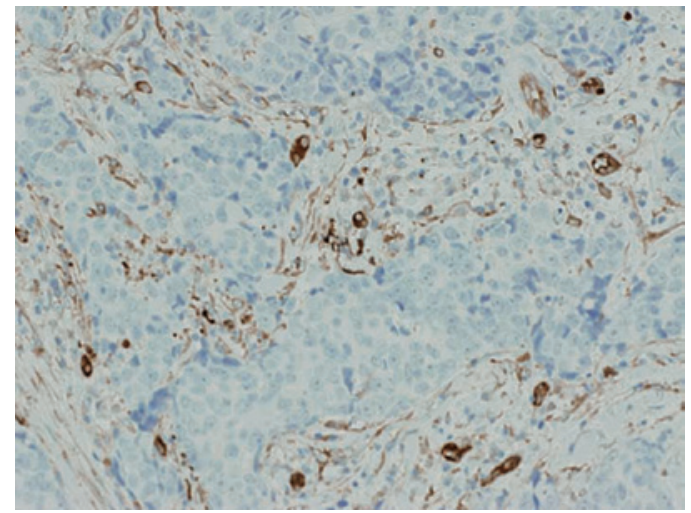

Figure 4. No epithelial immunostaining for fascin was identified in thymic carcinoma, although endothelial cells and a small number of DCs were stained by fascin. Magnification, x200.

immunohistochemical results are characteristic of specimens with lower Masaoka stage. Patients' age and lymph node metastasis did not correlate with any of the immunohistochemical results. As shown in Table IV, fascin ${ }^{+}$DCs correlated with the intensity of DCs and DC-cluster ratio. Intensity of DCs also showed positive correlations with DC-cluster ratio and fascin ${ }^{+}$ epithelium. DC-cluster ratio further correlated with fascin ${ }^{+}$ epithelium and intensity of epithelium. Statistical analysis also revealed that fascin ${ }^{+}$epithelium was positively correlated with intensity of epithelium.

With regard to the various immunohistochemical markers in the selected specimens, the presence of fascin ${ }^{+}$DCs in 
Table III. Correlations between clinicopathological data and immunohistochemical results of fascin.

\begin{tabular}{|c|c|c|c|c|c|}
\hline \multirow[b]{2}{*}{$\begin{array}{l}\text { Clinicopathological } \\
\text { data }\end{array}$} & \multicolumn{3}{|c|}{ Fascin $^{+}$DCs } & \multicolumn{2}{|c|}{ Fascin $^{+}$epithelium } \\
\hline & $\begin{array}{l}\text { Fascin }^{+} \mathrm{DCs} \\
\text { (per } 0.5 \mathrm{~mm}^{2} \\
\text { tissue area) }\end{array}$ & $\begin{array}{l}\text { Intensity of } \\
\text { DCs }\end{array}$ & $\begin{array}{l}\text { Ratio }(\%) \text { of } \\
\text { DC-cluster }\end{array}$ & $\begin{array}{c}\text { Ratio }(\%) \text { of positive } \\
\text { cell component: } \\
\text { Fascin }^{+} \text {epithelium }\end{array}$ & $\begin{array}{l}\text { Intensity of } \\
\text { epithelium }\end{array}$ \\
\hline Patients' gender & $\begin{array}{c}\mathrm{r}=-0.358 \\
\mathrm{p}=0.025\end{array}$ & ns & ns & ns & ns \\
\hline Patients' age & ns & ns & ns & ns & ns \\
\hline Complication from MG & $\begin{array}{c}\mathrm{r}=+0.478 \\
\mathrm{p}=0.002\end{array}$ & ns & ns & ns & ns \\
\hline Masaoka stage scores & ns & $\begin{array}{c}\mathrm{r}=-0.495 \\
\mathrm{p}=0.003\end{array}$ & ns & $\begin{array}{c}\mathrm{r}=-0.553 \\
\mathrm{p}=0.001\end{array}$ & $\begin{array}{c}\mathrm{r}=-0.381 \\
\mathrm{p}=0.026\end{array}$ \\
\hline Tumor diameter & $\begin{array}{c}\mathrm{r}=+0.376 \\
\mathrm{p}=0.029\end{array}$ & ns & ns & ns & ns \\
\hline Lymph node metastasis & ns & ns & ns & ns & ns \\
\hline Thymoma vs. Ca & $\begin{array}{c}\mathrm{r}=-0.361 \\
\mathrm{p}=0.024\end{array}$ & $\begin{array}{c}\mathrm{r}=-0.388 \\
\mathrm{p}=0.026\end{array}$ & $\begin{array}{c}\mathrm{r}=-0.342 \\
\mathrm{p}=0.033\end{array}$ & ns & ns \\
\hline Histologic variants & $\begin{array}{c}\mathrm{r}=-0.513 \\
\mathrm{p}=0.002\end{array}$ & ns & $\begin{array}{c}\mathrm{r}=-0.391 \\
\mathrm{p}=0.022\end{array}$ & ns & ns \\
\hline Epithelial origin & $\begin{array}{c}\mathrm{r}=+0.359 \\
\mathrm{p}=0.037\end{array}$ & $\begin{array}{c}\mathrm{r}=+0.373 \\
\mathrm{p}=0.030\end{array}$ & ns & ns & ns \\
\hline
\end{tabular}

Ca, carcinoma; MG, myasthenia gravis; DC, dendritic cell; ns, not significant ( $\mathrm{p}>0.05)$.

Table IV. Mutual correlations between different immunohistochemical results of fascin.

\begin{tabular}{|c|c|c|c|c|c|}
\hline & Fascin $^{+} \mathrm{DCs}^{\mathrm{a}}$ & Intensity of DCs & DC-cluster ratio & Fascin $^{+}$epithelium & Intensity of epithelium \\
\hline Fascin $^{+}$DCs & - & $\begin{array}{c}\mathrm{r}=+0.382 \\
\mathrm{p}=0.016\end{array}$ & $\begin{array}{c}\mathrm{r}=+0.780 \\
\mathrm{p}<0.001\end{array}$ & $\mathrm{~ns}$ & $\mathrm{~ns}$ \\
\hline Intensity of DCs & - & - & $\begin{array}{c}\mathrm{r}=+0.481 \\
\mathrm{p}=0.002\end{array}$ & $\begin{array}{c}\mathrm{r}=+0.487 \\
\mathrm{p}=0.002\end{array}$ & ns \\
\hline DC-cluster ratio & - & - & - & $\begin{array}{c}\mathrm{r}=+0.473 \\
\mathrm{p}=0.002\end{array}$ & $\begin{array}{c}\mathrm{r}=+0.325 \\
\mathrm{p}=0.043\end{array}$ \\
\hline Fascin $^{+}$epithelium & - & - & - & - & $\begin{array}{c}\mathrm{r}=+0.560 \\
\mathrm{p}<0.001\end{array}$ \\
\hline Intensity of epithelium & - & - & - & - & - \\
\hline
\end{tabular}

DC, dendritic cell; $\mathrm{ns}$, not significant $(\mathrm{p}>0.05)$. ${ }^{\mathrm{a}} \mathrm{per} 0.5 \mathrm{~mm}^{2}$ tissue area.

thymic neoplasms grossly corresponded to HLA-DR ${ }^{+}$DCs. However, a greater number of fascin ${ }^{+}$signals was observed in the cortical differentiation area, as noted in Types B1 and B2 thymomas. Fascin ${ }^{+}$DCs also occasionally co-expressed S100 protein in the medullary differentiation area, but did not express CD1a (Fig. 5A-D). CD1a was also positive in tumorinfiltrating lymphocytes of Types $\mathrm{AB}, \mathrm{B} 1$ and $\mathrm{B} 2$ thymomas, but negative in lymphocytes of other types and of carcinoma. Cytokeratin AE1/AE3 was generally positive in the epithelial components of thymic neoplasms (Fig. 5E). These results are shown in Table V. Notably, in normal thymus, both fascin and HLA-DR were positive for DCs in the medulla, while some fascin $^{+}$DCs in the cortex were negative for HLA-DR (Fig. 3B).

\section{Discussion}

The present study is the first to immunohistochemically assess the expression of fascin in thymoma and thymic carcinoma. Infiltrating DCs and tumor epithelium were confirmed to be positive for fascin in all thymoma tissues, whereas predominantly infiltrating fascin ${ }^{+}$DCs were identified in the thymic carcinoma tissues. S100 protein was formerly a commonly used marker for DCs. A number of immunohistochemical studies for S100 protein in thymomas were previously performed, and it was reported that abundant $\mathrm{S} 100^{+} \mathrm{DCs}$ were observed along with mature T-lymphocytes, especially in lymphocyticpredominant variants of thymoma $(10,25,26)$. However, S100 

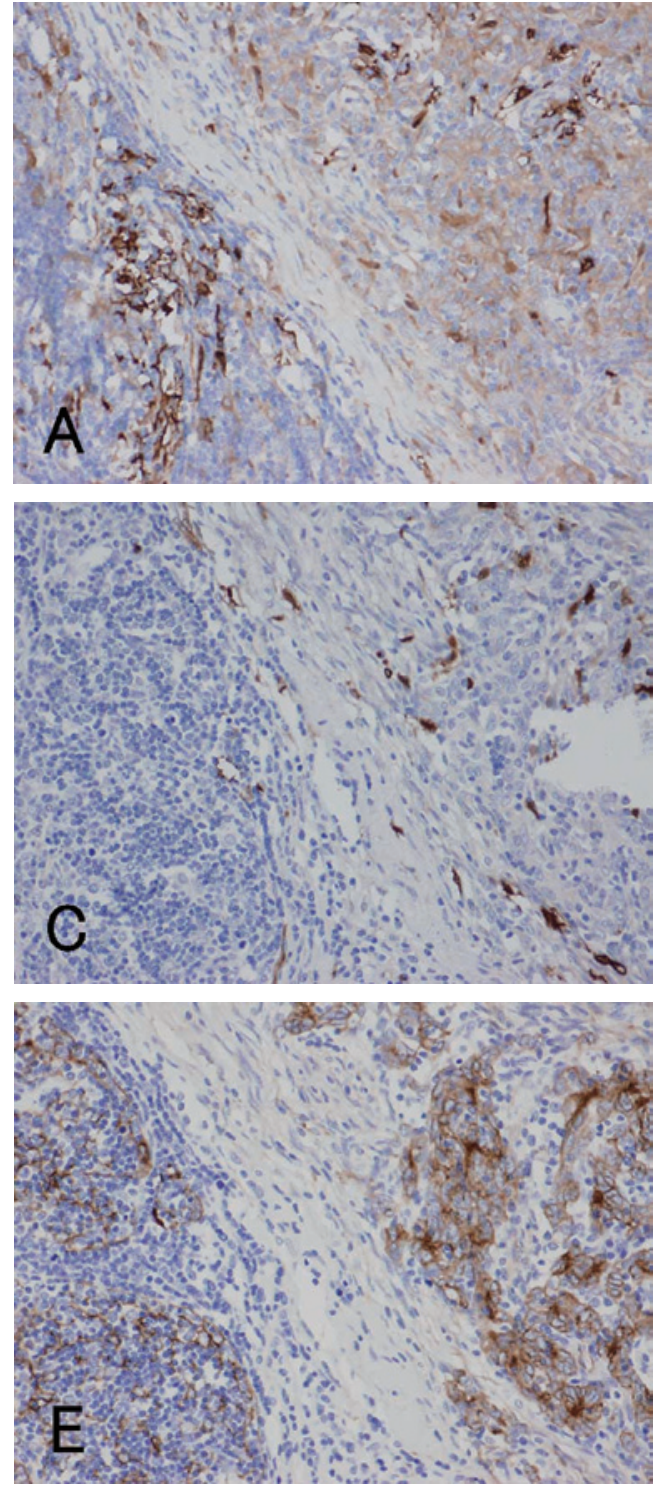

protein is positive in both immature and mature DCs. Immature DCs are capable of antigen uptake and processing, but are unable to stimulate naïve T-lymphocytes. On the other hand, mature DCs bind and stimulate T-lymphocytes (7). Fascin is an actin-bundling protein expressed by mature DCs and certain other cell types, including blood vessel endothelial cells $(12,27)$. In the present study, fascin ${ }^{+}$DCs did not correspond to $\mathrm{S} 100^{+}$DCs, particularly in the cortical differentiation area in the selected specimens. It has also been proposed that $\mathrm{S} 100^{+}$ DCs are interdigitating reticulum cells, which are abundant in the medullary differentiation area $(10,25)$. In the present study, fascin $^{+}$DCs were frequently identified in the cortical differentiation area, as verified by positive correlation between fascin ${ }^{+}$ DCs and epithelial origin, as well as with the co-expression of HLA-DR, a marker of antigen presentation (28). Therefore, we postulate that these fascin ${ }^{+}$mature DCs promote tumor immunity through antigen presentation. However, in the cortex of normal thymus, fascin ${ }^{+}$and HLA-DR cells were also observed, as reported by other authors (28). Furthermore, this study also revealed that fascin ${ }^{+}$DCs did not co-express CD1a, found mostly in immature DCs, although some thymic lymphocytes were positive for CD1a, as previously reported (9).
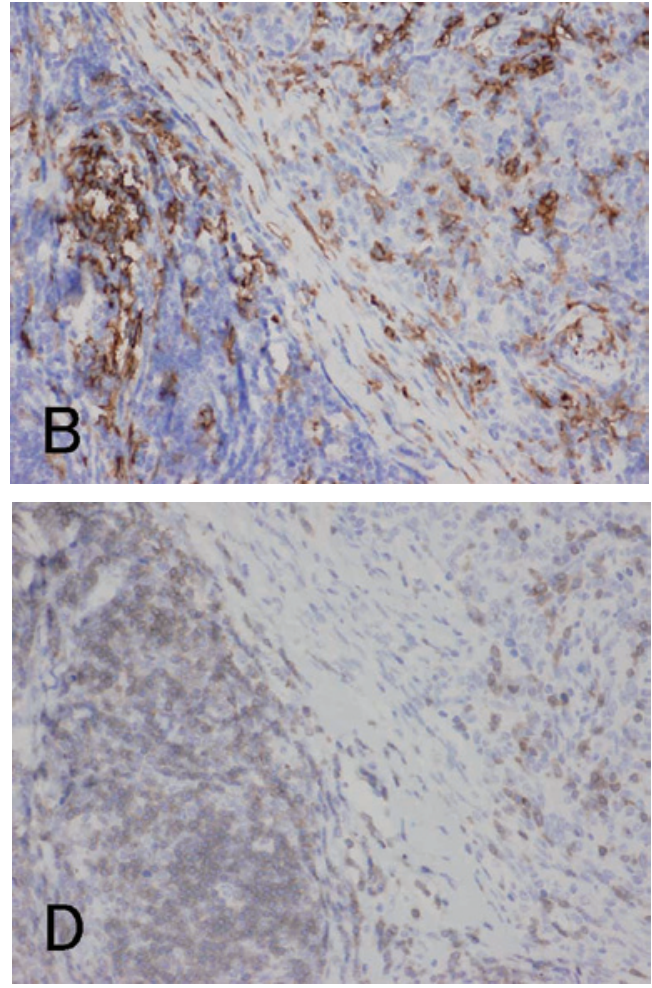

Figure 5. Borderline between Type A (upper right) and Type B areas (lower left) in Type AB thymoma (same fields in A-E). (A) Fascin immunostaining showed positive reactions for DCs and weak positive reactions for tumor epithelium. (B) HLA-DR immunostaining marked almost the same DCs as fascin staining. (C) Immunostaining for S100 protein labeled interdigitating reticulum cells in the medulla, but not DCs in the cortex. (D) CD1a immunostaining labeled lymphocytes, but not DCs. (E) Tumor epithelium was immunopositive for cytokeratin AE1/AE3. Magnification, x200.

The present study verifies that the observed fascin ${ }^{+}$ DC-clusters are mainly associated with benign thymic neoplasms and lymphocytic-predominant variants, since fascin ${ }^{+}$ DCs and DC-cluster ratio inversely correlated with thymoma vs. carcinoma and histological variants. The positive correlation found between fascin ${ }^{+} \mathrm{DC}$ and DC-cluster ratio indicates that the clusters are formed by numerous DCs. Whether the DCs infiltrate primarily or secondarily to lymphocytic infiltration remains to be clarified. However, if DCs infiltrate secondarily to lymphocytic infiltration, evenly-arranged structures, such as those observed in our cases, could not be explained. Therefore, it is more likely that mature DCs primarily capture tumorrelated antigens and process and present them to $\mathrm{T}$ lymphocytes for recruitment of other lymphocytes (7). Brunhuber et al, Ambe et al and Becker have reported that the amounts of tumor-infiltrating DCs and lymphocytes are interrelated in various tumors, such as melanoma, thyroid, esophageal, gastric and rectal cancers $(18,29,30)$.

With regard to the correlations between clinicopathological data and infiltrating mature DCs, it is noteworthy that fascin ${ }^{+}$DCs correlated with complications from myasthenia gravis. This may be due to the fact that only the cases 
Table V. Immunohistochemical results of various markers in selected specimens.

\begin{tabular}{lrcrrr}
\hline & \multicolumn{3}{c}{ Cell counts for DCs per 0.5 $\mathrm{mm}^{2}$ tissue area } \\
\cline { 2 - 5 } $\begin{array}{l}\text { Histological } \\
\text { classification }\end{array}$ & Fascin & HLA-DR & S100 protein & CD1a & $\begin{array}{c}\text { Cytokeratin AE1/AE3 } \\
\text { in epithelial component }\end{array}$ \\
\hline Type A & 39 & 38 & 3 & 3 & Diffusely positive \\
Type AB & 91 & 155 & 40 & 123 & Diffusely positive \\
Type B1 & 134 & 60 & 56 & 0 & Diffusely positive \\
Type B2 & 112 & 38 & 39 & 10 & Diffusely positive \\
Type B3 & 14 & 19 & 3 & 21 & Occasionally positive \\
Carcinoma & 8 & 7 & 20 & 13 & Diffusely positive \\
\hline
\end{tabular}

DC, dendritic cell.

with Types AB, B1 and B2 thymomas, which are relatively lymphocyte-rich variants, experienced complications from myasthenia gravis in the present study. This result is in accordance with the fact that myasthenia gravis is frequently associated with Types AB, B2 and B3 thymomas (31). Alternatively, the frequent infiltration of mature DCs in thymomas may explain the reason for the more favourable prognoses of thymoma patients with myasthenia gravis, which may initiate tumor immunity, than patients with a poor prognosis (4). Fascin ${ }^{+}$DCs also correlated with patients' gender, thus indicating that mature DCs frequently infiltrate into thymic neoplasms of male patients. However, this may be a confounding factor, as 7 out of 8 patients with complications from myasthenia gravis were males in the present study. The reason for the positive correlation between fascin ${ }^{+}$DCs and tumor diameter may be that larger tumors are likely to be more frequently recognized by DCs.

With regard to the fascin expression level in DCs, it has been reported that increased fascin expression is associated with enhanced cell motility (14). In the present study, intensity of DCs correlated with epithelial origin. Therefore, cortical epithelium may strongly induce mobile DCs. Cortical epithelium in normal thymus is known to be associated with maturation of $\mathrm{T}$ lymphocytes, by expressing $\mathrm{MHC}$ I and II molecules (28). Modified MHC molecules during tumor formation may be recognized as antigens by DCs, thus activated DCs may express increased fascin. Intensity of DCs further correlated with fascin ${ }^{+}$DCs and DC-cluster ratio, suggesting that activated DCs tend to aggregate and recruit lymphocytes, resulting in evenly arranged DC structures. Intensity of DCs exhibited a negative correlation with Masaoka stage scores, indicating that activated DCs induce immunoreaction and suppress the invasiveness of the tumor.

Of note is that the ratio of fascin ${ }^{+}$epithelium was also inversely correlated with Masaoka stage scores in the present study. By contrast, it has been reported that fascin ${ }^{+}$tumor epithelium has strong invasiveness with poorer prognosis in various carcinomas, such as ovarian, breast, pancreas, lung, cutaneous, brain, gastrointestinal, thyroid, prostate, urothelial, intrahepatic cholangiocarcinoma and skin tumors (14-23). The significance of epithelial fascin expression has been reported to be associated with invasiveness and metastasis, since it aids in cell migration and proliferation through increases in lamellipodial and filopodial cell protrusions (15). Moreover, fascin $^{+}$tumor epithelium has been reported to express matrix metalloproteinase-9 to dissolve the stroma during migration (20). However, it has also been reported that epithelial fascin expression does not affect the prognosis in extrahepatic and hilar cholangiocarcinoma (20). We confirmed that fascin ${ }^{+}-$ activated tumor epithelium may proliferate $(14,15,19,21)$ since there was a positive correlation between intensity of epithelium and fascin ${ }^{+}$epithelium. However, in the present study, fascin ${ }^{+}$ epithelium also correlated with intensity of DCs and DC-cluster ratio. Furthermore, intensity of epithelium positively correlated with DC-cluster ratio and inversely correlated with Masaoka stage scores. Therefore, in thymic neoplasms, invasive tumor epithelium with a wider proportion and higher intensity of fascin positivity probably induces tumor immunity through recognition by mature DCs. This may be one reason for the relatively favorable prognosis of thymoma in general (2).

It is noteworthy that only 1 out of 5 thymic carcinomas expressed epithelial fascin. Moreover, fascin ${ }^{+}$DCs, DC-cluster and intensity of DCs were inversely correlated with thymoma vs. carcinoma, indicating that the amount and intensity of fascin expression in DCs as well as cluster-formation are associated predominantly with benign thymic neoplasms. These results also indicate that malignant transformation of the thymic neoplasm is associated with a paucity of activated DCs, presumably due to the poorer epithelial expression of fascin as mentioned earlier. Alternatively, it is also speculated that thymic carcinomas tend to proliferate as a block rather than via infiltration, thus escaping surveillance by DCs, since it has been reported that fascin is not expressed in the metastatic foci of colon carcinomas, whereas it is expressed in the primary tumors (32). However, since the number of investigated thymic carcinomas in the present study was small, further studies with larger numbers of cases are required to elucidate the significance of fascin expression of thymic carcinomas.

In conclusion, fascin expression in DCs and tumor epithelium of thymic neoplasms was investigated, and it was revealed that the amount and/or higher intensity of fascin levels in DCs with the formation of clusters were associated with lymphocyte-rich variants and the cortical differentiation of thymoma with complications from myasthenia gravis. The quantity and 
strong intensity of fascin ${ }^{+}$epithelium were associated with cluster-forming infiltrating fascin ${ }^{+}$DCs and favorable prognosis, as assessed by the Masaoka staging system, thus fascin ${ }^{+}$ epithelium may promote tumor immunity.

\section{Acknowledgements}

This study was partly supported by the Tokyo Medical University Cancer Research Foundation.

\section{References}

1. Kurup A and Loehrer PJ Sr: Thymoma and thymic carcinoma: therapeutic approaches. Clin Lung Cancer 6: 28-32, 2004.

2. Duwe BV, Sterman DH and Musani AI: Tumors of the mediastinum. Chest 128: 2893-2909, 2005.

3. Marx A, Ströbel P, Zettl A, Chan JKC, Müller-Hermelink HK, Harris NL, Kuo TT, Shimosato Y and Engel P: Thymomas. In: Pathology and Genetics of Tumours of the Lung, Pleura, Thymus and Heart (WHO classification of tumors series). Travis WD, Brambilla E, Müller-Helmelink HK and Harris CC (eds). IARC Press, Lyon, France, pp152-171, 2004.

4. Margaritora S, Cesario A, Cusumano G, Meacci E, D'Angelillo R, Bonassi S, Carnassale G, Porziella V, Tessitore A, Vita ML, Lauriola L, Evoli A and Granone P: Thirty-five-year follow-up analysis of clinical and pathologic outcomes of thymoma surgery. Ann Thorac Surg 89: 245-252, 2010.

5. Masaoka A, Monden Y, Nakahara K and Tanioka T: Follow-up study of thymomas with special reference to their clinical stages. Cancer 48: 2485-2492, 1981.

6. Okumura M, Miyoshi S, Takeuchi Y, Yoon HE, Minami M, Takeda SI, Fujii Y, Nakahara K and Matsuda H: Results of surgical treatment of thymomas with special reference to the involved organs. J Thorac Cardiovasc Surg 117: 605-613, 1999.

7. Gerner MY and Mescher MF: Antigen processing and MHC-II presentation by dermal and tumor-infiltrating dendritic cells. J Immunol 182: 2726-2737, 2009.

8. Kornstein MJ, Hoxie JA, Levinson AI and Brooks JJ: Immunohistology of human thymomas. Arch Pathol Lab Med 109: 460-463, 1985.

9. Pomplun S, Wotherspoon AC, Shah G, Goldstraw P, Ladas G and Nicholson AG: Immunohistochemical markers in the differentiation of thymic and pulmonary neoplasms. Histopathology 40: $152-158,2002$

10. Lee D and Wright DH: Immunohistochemical study of 22 cases of thymoma. J Clin Pathol 41: 1297-1304, 1988.

11. Pinkus GS, Pinkus JL, Langhoff E, Matsumura F, Yamashiro S, Mosialos G and Said JW: Fascin, a sensitive new marker for Reed-Sternberg cells of hodgkin's disease. Evidence for a dendritic or B cell derivation? Am J Pathol 150: 543-562, 1997.

12. Kurata A, Terado Y, Schulz A, Fujioka Y and Franke FE: Inflammatory cells in the formation of tumor-related sarcoid reactions. Hum Pathol 36: 546-554, 2005.

13. Machesky LM and Li A: Fascin: invasive filopodia promoting metastasis. Commun Integr Biol 3: 263-270, 2010.

14. Darnel AD, Behmoaram E, Vollmer RT, Corcos J, Bijian K, Sircar K, Su J, Jiao J, Alaoui-Jamali MA and Bismar TA: Fascin regulates prostate cancer cell invasion and is associated with metastasis and biochemical failure in prostate cancer. Clin Cancer Res 15: 1376-1383, 2009.

15. Iguchi T, Aishima S, Umeda K, Sanefuji K, Fujita $N$, Sugimachi K, Gion T, Taketomi A, Maehara Y and Tsuneyoshi M: zFascin expression in progression and prognosis of hepatocellular carcinoma. J Surg Oncol 100: 575-579, 2009.
16. Yildiz L, Kefeli M, Aydin O and Kandemir B: Fascin expression in melanocytic lesions of the skin. Eur J Dermatol 19: 445-450, 2009.

17. Zhang FR, Tao LH, Shen ZY, Lv Z, Xu LY and Li EM: Fascin expression in human embryonic, fetal, and normal adult tissue. J Histochem Cytochem 56: 193-199, 2008.

18. Brunhuber T, Haybaeck J, Schäfer G, Mikuz G, Langhoff E, Saeland S, Lebecque S, Romani N and Obrist P: Immunohistochemical tracking of an immune response in mammary Paget's disease. Cancer Lett 272: 206-220, 2008.

19. Ozerhan IH, Ersoz N, Onguru O, Ozturk M, Kurt B and Cetiner S: Fascin expression in colorectal carcinomas. Clinics 65: 157-164, 2010

20. Onodera M, Zen Y, Harada K, Sato Y, Ikeda H, Itatsu K, Sato H, Ohta T, Asaka M and Nakanuma Y: Fascin is involved in tumor necrosis factor-alpha-dependent production of MMP9 in cholangiocarcinoma. Lab Invest 89: 1261-1274, 2009.

21. Xie JJ, Xu LY, Wu JY, Shen ZY, Zhao Q, Du ZP, Lv Z, Gu W, Pan F, Xu XE, Xie D and Li EM: Involvement of CYR61 and CTGF in the fascin-mediated proliferation and invasiveness of esophageal squamous cell carcinomas cells. Am J Pathol 176: 939-951, 2010.

22. Kefeli M, Yildiz L, Kaya FC, Aydin O and Kandemir B: Fascin expression in uterine smooth muscle tumors. Int $\mathrm{J}$ Gynecol Pathol 28: 328-333, 2009.

23. Durmaz A, Kurt B, Ongoru O, Karahatay S, Gerek M and Yalcin S: Significance of fascin expression in laryngeal squamous cell carcinoma. J Laryngol Otol 124: 194-198, 2010.

24. Marchevsky AM, Gupta R, McKenna RJ, Wick M, Moran C, Zakowski MF and Suster S: Evidence-based pathology and the pathologic evaluation of thymomas: the World Health Organization classification can be simplified into only 3 categories other than thymic carcinoma. Cancer 112: 2780-2788, 2008.

25. Kondo K, Mukai K, Sato Y, Matsuno Y, Shimosato Y and Monden Y: An immunohistochemical study of thymic epithelial tumors. III. The distribution of interdigitating reticulum cells and S-100 beta-positive small lymphocytes. Am J Surg Pathol 14: 1139-1147, 1990

26. Rouse RV and Weiss LM: Human thymomas: evidence of immunohistologically defined normal and abnormal microenvironmental differentiation. Cell Immunol 111: 94-106, 1988.

27. Kurata A, Terado Y, Izumi M, Fujioka Y and Franke FE: Where does the antigen of cutaneous sarcoidosis come from? J Cutan Pathol 37: 211-221, 2010.

28. Wakimoto T, Tomisaka R, Nishikawa Y, Sato H, Yoshino T and Takahashi K: Identification and characterization of human thymic cortical dendritic macrophages that may act as professional scavengers of apoptotic thymocytes. Immunobiology 213: 837-847, 2008 .

29. Ambe K, Mori M and Enjoji M: S-100 protein-positive dendritic cells in colorectal adenocarcinomas. Distribution and relation to the clinical prognosis. Cancer 63: 496-503, 1989.

30. Becker Y: Anticancer role of dendritic cells (DC) in human and experimental cancers - a review. Anticancer Res 12: 511-520, 1992.

31. Müller-Hermelink HK, Möller P, Engel P, Menestrina F, Kuo TT, Shimosato Y, Ströbel PH, Asamura H, Marx A, Masaoka A, Harris NL and Sobin LH: Tumours of the thymus. In: Pathology and Genetics of Tumours of the Lung, Pleura, Thymus and Heart (WHO classification of tumors series). Travis WD, Brambilla E, Müller-Helmelink HK and Harris CC (eds). IARC Press, Lyon, France, pp145-151, 2004.

32. Vignjevic D, Schoumacher M, Gavert N, Janssen KP, Jih G, Laé M, Louvard D, Ben-Ze'ev A and Robine S: Fascin, a novel target of beta-catenin-TCF signaling, is expressed at the invasive front of human colon cancer. Cancer Res 67: 6844-6853, 2007. 